certain basic needs that have to be met at each stage of the resettlement process if the immigrant is to adjust to the new environment. In this model, adjustment phases are intended to provide a basis for social service programming "which will provide need gratification at the appropriate time and thus facilitate adjustment."

Repetition is a distraction in this volume, most noticeably within the chapters on psychological and economic adaptation, but it is understandable, given that the two areas are so often interdependent. A section on dreams, though interesting enough, doesn't do as claimed. It promises a 'systematic analysis' of dreams to provide important clues to unresolved psychological and emotional problems; in fact, the dreams seem to have been used more to confirm or illustrate the previous findings.

These minor problems do not detract from the value of Uprooting. In fact, the book should be of particular interest to a wide range of researchers, from students newly engaged in refugee issues or to anyone working in the field. Indra's excellent bibliography provides a comprehensive listing of available books, articles, reports, papers, and unpublished manuscripts. The book is particularly useful, given the recency of this field of study and the problem of locating scattered or difficult to locate background and historical information. Although the content focuses on the Indochinese, it contains much to inform and update those working with other immigrant or refugee groups.

[Marilyn Walker is a Doctoral Candidate in Anthropology, Faculty of Graduate Studies at York University, and a Research Associate of the Refugee Documentation Project.]

\section{New Book Recommendation}

The Refugee Documentation Project recommends the recent publication of Dr. Jean Burnet with Dr. Howard Palmer: Coming Canadians : An Introduction to a History of Canada's Peoples. Soft cover paperback, 253 pages, includes Tables, 32 pages of photographs representative of Canada's multicultural society, bibliography and index; $\$ 12.95$. Published by McLelland and Stewart in association with the Multiculturalism Program, Department of the Secretary of State.

Part One is devoted to immigration and settlement in two segments: to 1880 , and from 1880-1980. Part Two deals with Canada's major institutions; Part Three with other institutions and the maintenance of identity. The authors are erudite exponents of ethnicity in Canada in general, and of Canadian multiculturalism in particular. References to refugees include the historical background of their forced displacement from one culture to another, cross-cultural analyses of discrimination from host country policy and peoples, as well as across other groups, and within their own ethnocultural groups. And like other 'Coming Canadians,' acknowledgement is given to the past and present refugees' professional and cultural contributions to the Canadian economy and society.

Noreen Spencer-Nimmons

\section{New Publications}

Immigration and Ethnic Conflict. Anthony H. Richmond. 1988, 184pp, $216 \mathrm{x}$ $138 \mathrm{~mm}$, tables and figures; hardcover. Distributed in Canada by McClelland \& Stewart, Toronto.

Southeast Asian Refugee Youth: An Annotated Bibliography - Compiled by Ruth E. Hammond and Glenn L. Hendricks. Number six in a series of occasional papers. 1988, 143pp, Introduction, Abstracts by subject, and Author Index. Published by Southeast Asian Refugee Studies Project. Center for Urban and Regional Affairs, University of Minneapolis, Minneapolis, Minnesota.

\title{
Refugee Women Workshop Weekend
}

On June 17 - 19, 1988, at the Glendon College campus of York University, a unique and highly successful multicultural event occurred. The event was unique because it brought together refugee women from diverse ethnocultrual backgrounds to work at the 'grass roots' level on issues of adjustment and adaptation to Canadian society. Refugee women from around the Province of Ontario were invited to address the gaps and inadequacies in present service deliveries, from their perception of the situation. At an opening session, the women wrote the agenda for the weekend. The women were subsidized to attend, as were their children. Daycare and children's programmes were provided and a special cultural evening was included in the Workshop Weekend. The refugee women presented their recommendations for alternative solutions, networking, and self-help mechanisms at the final plenary session on Sunday afternoon.

The Workshop Weekend represents Phase I of the ongoing "Refugee Women in Canada Project" which is co-sponsored by the Refugee Documentation Project, the Working Group for Refugee Women (a sub-group of the Canadian Council for Refugees), and the YWCA Metropolitan Toronto Refugee Committee. Funding for Phase I was contributed by the Ontario Women's Directorate, the Canada Employment and Immigration Commission, and by Levi Strauss (Canada) Inc. Funds are presently being sought for Phase II, the major research component of the project.

In Phase II, refugee women will be invited to participate in 'team' research. It is hoped that the Project will conclude in Phase III with a national conference during which a full report based on the work of Phase I and II will be presented.

We welcome the input of refugee women who would wish to participate in the 'Project' and encourage them to contact us. The co-sponsoring groups respecfully invite potential funders to respond to this important work. Please contact the Refugee Documentation Project, York University, 4700 Keele Street, North York, Ontario, M3J 1P3, or telephone (416) $736-5061$. 
Library: Serials Dept

University of Toronto

TORONTO ON

M5S 1 A5

\section{Cal \\ Call For Papers: Special Issue

\author{
SOUTHEAST ASIAN JOURNAL OF \\ SOCIAL SCIENCE
}

The Editors of the Southeast Asian Journal of Social Science currently invite article-length manuscript submissions for a special issue on the theme of 'Indochinese Refugee Experience and its Asian Response'. It is intended in the issue to develop an 'Asian' perspective on the Southeast Asian refugees phenomenon. The focus will be primarily on the plight of refugees in transit camps in the Southeast Asian region, as well as those already resettled in other parts of Asia (e.g. China and Japan) and Australia.

The Journal being multi-disciplinary in nature, we welcome contributions from sociologists, anthropologists, psychologists, political scientists, geographers, historians as well as legal scholars. Contributors, among others, may want to submit for publication consideration papers on: problems in definition of a refugee; refugee camps in countries of first asylum in the region; refugee resettlement in host countries in Asia; comparative analysis of refugee and external affairs policies in various Asian countries; legal analysis of national as well as international laws, statutes and conventions pertaining to the Southeast Asian refugees; implications of the Southeast Asian refugees phenomenon for human rights in Asia; and assessment of the theoretical and practical possibility of repatriation, and its consequences.
The special issue is targeted for publication in September, 1989. The deadline for article submissions is March 30, 1989. All submissions should be in duplicate and typed double-spaced. The recommended manuscript length is approximately thirty pages, including notes and references.

Manuscripts and inquiries should be directed to:

Dr. Kwok B. Chan

Southeast Asian Journal of Social Science

Department of Sociology

National University of Singapore

10 Kent Ridge Crescent

Singapore 0511

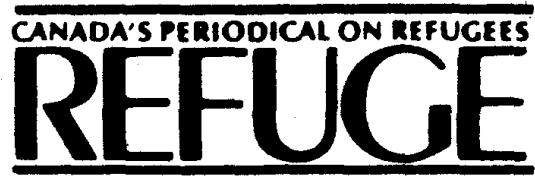

c/o Relugee Documentation Project. York University

4700 Keele Street. North York. Ontario M3J 193

I wish to become a friend of the Refugee Documentation Project for the 19881989 academic year. I understand that all friends receive Refuge as well as information on the research activities of the RDP. My cheque for $\$ 25$ (or ) made payable to the Refugee Documentation Project is enclosed.

Name Organization

Address

City Province or Stute

Country Postal Code 